\title{
Annotation of Dynamic Identities in Interactive Aesthetics
}

\author{
Ming-Chieh Hsu \\ Department of Information Communication, Yuan Ze University, Chung-Li, Taiwan \\ Email: minghsu@saturn.yzu.edu.tw
}

Received August $26^{\text {th }}$, 2013; revised September $30^{\text {th }}, 2013$; accepted October $10^{\text {th }}, 2013$

\begin{abstract}
Copyright (c) 2013 Ming-Chieh Hsu. This is an open access article distributed under the Creative Commons Attribution License, which permits unrestricted use, distribution, and reproduction in any medium, provided the original work is properly cited. In accordance of the Creative Commons Attribution License all Copyrights (c) 2013 are reserved for SCIRP and the owner of the intellectual property Ming-Chieh Hsu. All Copyright (C) 2013 are guarded by law and by SCIRP as a guardian.
\end{abstract}

\begin{abstract}
With a variety of platforms and media vehicles, designers not only have a challenge on new concepts such as varied expression forms, elements, principles, and aesthetic concepts, they also have to take into account users' cognitive tendencies and social media aspects during the design thinking process, especially in trying to enhance the user experience. Dynamic identities aim to improve a traditionally static visual experience with a multi-dimensional angle. In addition, not only does interaction design express creativity and cognitive philosophy via all senses: sight, touch, smell, hearing, and taste, it also combines psychological perception with aesthetics. "Interaction" is a process of communication, which influences both cognition and mentality. This study is based on three key factors/aspects of interaction aesthetics: cognitive level of recognition, physical level of functionality, and psychological level of emotion. Forty-four dynamic identities from January 2011 to July 2012 were studied with a case study method, analyzing the design process and related principles. Through focus groups and in-depth interviews, this study investigates the concept of interaction design to classify three types of dynamic identities: "functionality", "entertainment", and "identification". Different characteristics of media and platforms are analyzed by framing the corporate identity system to form a unique dynamic identity. This paper proposes that functionality dynamic identities give rise to the "customization" and "modularity" design principles; whereas entertainment dynamic identities bring forth the "aesthetically pleasing" and "entertaining" design principles. Moreover, through the user-centered design experience a "personalized" design principle is born.
\end{abstract}

Keywords: Dynamic Identity; Interactive Aesthetic; Interaction Design

\section{Introduction}

Communication techniques experienced numerous revolutionary changes. In the late 20th century, computers brought forth the information revolution, which made the prospect of information society more immediate. With the aid of digital media, communication media has developed several variations and this made people change the method of information-collecting and reading, also change the channel for industry brand communications, and marked a big step in identity strategy (Wang, 2005). The creative process for brand identity needs to combine investigation, tactical thinking, excellent design, and management techniques, which is a scientific process (Wheeler, 2009). Digital media and interactive media are different from traditional print media, the communication angle, method and audience relationship are different as well. Therefore, a traditional static logo is harder to fulfill the need of multimedia communication. Interaction and immediacy make a logo more vital, and the relationship between the network and audience is closer (Liu \& Guan, 2009). The diversified form of digital media changes the techniques of brand identity design, and dynamic identity is one of the best applications to present a company's brand image, and through the superiority of digital media, a company can more easily win the competition (Budelmann, Kim, \& Wozniak, 2010; Wheeler, 2009). Therefore, the influence of interactive design aesthetics on dynamic brand identity, the research of design thinking and design principles are the main motive of this study.

\section{Literature Review}

\section{Brand Identity and Dynamic Brand Identity System}

A successful industry brand always has an excellent industry identity system, with the business activity and culture that signify this business, to increase symbol recognition through different media (Lin, 1985). Brand identity is a brand's external image which a business organization expects to represent itself, it is able to make consumers easily identify its uniqueness, significance, value, and personality (Kapferer, 1992; Aaker \& Joachimsthaler, 2002). Through products, or the function, name, logo and visual system of service, marketing messages are sent, consumers can see, touch, own, hear, and watch the logo moving, and all kinds of methods are used to establish it in different media (Upshaw, 2000; Wheeler, 2009).

The dynamic identity shown in digital media almost has the element of timeliness (animation and dynamic image), and in its creation, the designer should notice if it definitely provides the essence and character of the brand, and transfers the connotation of a static image into a dynamic image presentation. In presenting the dynamic identity, dynamic method should be 
used to state and perform the brand, so the brand's rhythm and speed determine the result and also the identity's appeal (Wang, 2005; Mollerup, 1999; Rawsthorn, 2008; Wheeler, 2009). With the booming of mobile devices, the development of dynamic brand identity will change along with the development of technology, furthermore, for customers, there is room to explore the brand image from within the dynamic brand identity. In the brand identity field, using animation or dynamic images combined with trademarks for visual identity and image design, and thinking of different communication media and platform's character while designing a whole brand identity concept will create a dynamic identity with unique style (Hsu \& Chen, 2011).

Based on many scholars' research, including the analysis of brand strategy of various industries, clarifying characteristics of industry, consumer markets position, market segment analysis, and strategic motivations, goals or market cycle targeting, etc., now is the age of diverse media and platforms, whether using visual or tactile elements of the brand, cross-cultural issues should be addressed, especially for the element of brand identity, such as naming, the difference between symbolic object and brand attitude; the market segmentation positioning, color, the difference of visual culture preferences; avoiding the conflict of pronunciation and homonyms; and the expression of visual image across language barriers (Liu \& Guan, 2009; Vaid, 2003; Wheeler, 2009).

\section{Interactive Design Aesthetics and Dynamic Brand Identity}

Tremayne \& Dunwoody (2001) found interactivity to be a cognitive process, and the perceived interactivity has influenced the effect of message-perceiving strategy in users. Understanding the need of users confirms the main goal, usability is the core of interactive design, and the goal of user experience is the quality of defining the user experience, which is a subjective experience containing the feeling within the interaction of users and products. Many scholars brought up the theories that interactive design is not only concerned about the high efficiency or high productivity of the design, but concerned more about the characteristics of interactive design, such as being satisfying, enjoyable, fun, entertaining, helpful, motivating, aestheticallypleasing, supportive of creativity, rewarding, emotionally-fulfilling (Norman, 2007; Sharp, Rogers, \& Preece, 2009).

In perceptual stimulation, everyone's identity and interpretation is based on the scientific perception experiment, when looking at the brand, we first recognize the shape. When type is interpreted for its meaningfulness, the visual image is the first to be remembered and recognized. The brain reads color after it registers shape, and before it reads the form, therefore an easy-to-recognize shape is necessary; color can arouse feelings connecting to the brand; then comes the form, when brain is in the process of dealing with visual language over and over again, it will notice details in the content (Wheeler, 2009). Observing from symbols' alterability, in an identity system, every element of symbolic expression could be highly stable, and could also be altered randomly. However, a dynamic style often creates a creative aesthetic, and provides a unique charm (Wang, 2005). The scholar Wheeler further interpreted the brand identity design process as thinking of the visual dimension of the brand trademark, such as a main color and any secondary color combinations, scale, proportion, typography, imagery and the per- formance of motion, form, style, and focus in media like photography, illustration or iconography. And for the tactile dimension of the brand identity system, including experience and emotion, one is media texture, hand touch, weight; the other are interactive qualities such as package structure, or the sense of hearing and smell, and how to arouse in people the association and recognition of hearing and smelling (Vaid, 2003).

Stone (2010) specifically brought up the elements of design aesthetics, he explained that design aesthetics is a design process, meaning that design elements should thoughtfully fit with public awareness and emotion. This study base on the theory of Norman (2004), and also integrate the scholars' discussion, the interactive design aesthetics originates from user experience, and its formed elements: 1) cognitive level of recognition; 2) physical level of functionality; 3) psychological level of emotion (Norman, 2007; Ross, Overbeek, Wensveen, \& Hummels, 2008; Locher, Overbeeke, \& Wensveen, 2010; Stone, 2010). Further analyze the design thinking and principle of dynamic brand identity.

\section{Research Method and Case Analysis}

This study mainly researches the influence of interactive design aesthetics on the dynamic brand identity system. It researches and generalizes 44 cases of dynamic brand identity around the world, analyzes the relationship between interactive design aesthetics and design thinking, design principles; establishes the classification and the design thinking of the dynamic brand identity system through three experts' focus group seminars (5 - 7 person). Preliminary data is based on the analysis of the coding from document review, from exploratory research, developing a more apparent concept, establishing priority, developing an operative definition, and expecting to have further understanding of the study subject. This study uses case analyses based on related literature in design aesthetics and interactive design aesthetics, integrates the elements of interactive design aesthetics, and analyzes the design thinking and design principle of 44 cases of dynamic brand identity from a cognitive level of recognition, a physical level of functionality, and psychological level of emotion (see Figure 1).

\section{Operative Definition}

- The cognitive level of recognition which includes recogni-

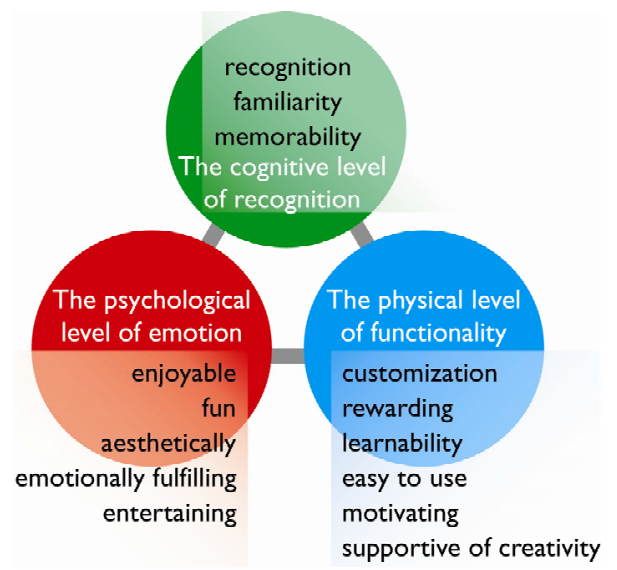

Figure 1.

The elements of interactive design aesthetics. 
tion, familiarity and memorability; design aesthetics refers to the relationship between various shapes, colors and material, the interaction between proportion, contrast, and size, also the visual balance of order, diversity, and rhythm (Stamps, 2000).

- The physical level of functionality which includes customization, which should be rewarding, easy to use, motivating and supportive of creativity; interactive design aesthetics is visual, tactile perception is used at the same time, as a designer we hope to understand how to achieve the goal of usability (Locher et al., 2010; Stone, 2010).

- The psychological level of emotion which includes enjoyable, fun, aesthetically pleasing, emotionally fulfilling and entertaining qualities. Interactive design aesthetics means pleasure and fun in aesthetics design, and designers design to achieve interaction and integration (Norman, 2007).

In addition, this study is based on related literature for brand identity system design principles, there are 16 design principles for the dynamic brand system, which are simplicity, globalization, sustainability, legibility, consistency, uniqueness, attention, description, repetition, flexibility, modernness, extendability, systematics, aesthetics, renovation and understanding, and will be clarified in these 44 cases.

\section{Dynamic Brand Identity Case Analyses}

Synthesizing 44 cases of dynamic brand system identity, and analyzing by industry, which includes information industry, such as cloud service, mobile device platform, mobile application and information science, communications industry and telecommunications industry; traditional industries such as the wheel manufacturing industry and consumer goods company; service industries, such as general merchandise, hair salon and accounting firm, agencies and digital printing company; cultural education industry, such as music hall, museum, exhibition, school and seminar, and emerging technology-based media lab; tourism industry, such as design of an international city image and a tourist city image; the biotechnology industry, welfare organization and political organization. In the global dynamic trademark distribution, there is USA and Canada in the USA \& Canada area; Switzerland, Finland, UK, Norway, Portugal, France, Spain, Netherlands and Germany in Europe; Australia, India, Korea, and Russia in Asia; and Brazil in South America.

1) Cognitive level of recognition

As for cultural education industry, take the Finland Playlab studio for an example. Playlab is a practical place for creation, which focuses on fun and is the combination of community, education, entertainment and activity. Their subtitle, "The Imagination Gym" refers to devising activities which challenge people to engage with both sides of their brains, and the full scope of their creativity. With multi-disciplinary skills they tackle marketing and promotion projects for business, retail, museums, galleries and public organizations. The brand identity uses words and symbols, Playlab is a workshop space aimed to be a creative playground for stressed adults, and aimed at creating a playful space. Their identity system and website was designed by Mind Design Company in London (2011). On the envelope and letterhead the actual logo is just blind embossed, and illustrations use a mixture of scientific elements and random fun images. The stationery is printed in red, yellow and blue, and the address details are filled in using a rubber stamp.
Logo changes when applied to different media (see Figure 2).

As for the telecommunications industry, take Nokia Siemens Networks for an example, it is the second biggest mobile telephone network equipment manufacturer in the world. The merger of Nokia and Siemens' network businesses presented a uniquely challenging branding opportunity - that of creating an entirely new identity for a brand that would be a €6 billion market leader-Nokia Siemens Networks. For Nokia Siemens Networks, an identity that thrives across all platforms was successfully created-a living, breathing brand that is multi-sensorial, multi-dimensional and highly impactful. The brand was launched in February 2007 with a film produced as part of the branding process, which was lead-designed by Moving Brands (2007). A full identity system was created that worked across print, onscreen, audio and interactive media. Deliverables included logo, mnemonic and Sonic Mnemonic ${ }^{\circledR}$ (moving and audio logo), a suite of sonic assets (including music and ringtones), brand films, photography, stationery, typography, signage, livery, environments, and pictograms, as well as look and feel and usage guidelines across all touch-points (see Figure 3).

Design aesthetics is the recognition concept of sensory, is a theory of free art, is art thinking of all kinds of beauty, a rational art, which is similar to philosophy thinking; moreover, it is a science of sensory recognition (Baumgarten, 1987). From the operational definition of the cognitive level of recognition and design principles of the traditional brand identity system, the identification, attentiveness, and visual consistence of brand identity is noted, therefore, we classify this type of dynamic identity as "identification" dynamic brand identity.

2) Physical level of functionality

Take the MIT media lab for example. Its new visual identity is inspired by the community it comprises: Highly creative people from all kinds of backgrounds come together, inspire each other and collaboratively develop a vision of the future. Each of the three shapes stands for one individual's contribution, and the resulting shape represents the outcome of this pro-

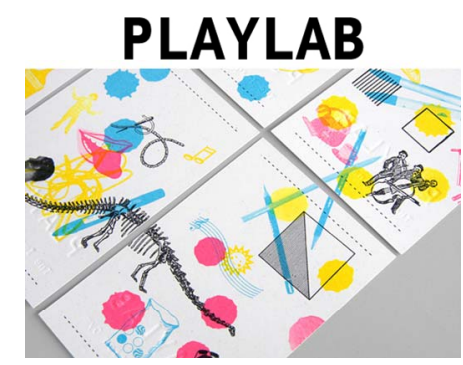

Figure 2.

Playlab identity, mind design (2011).

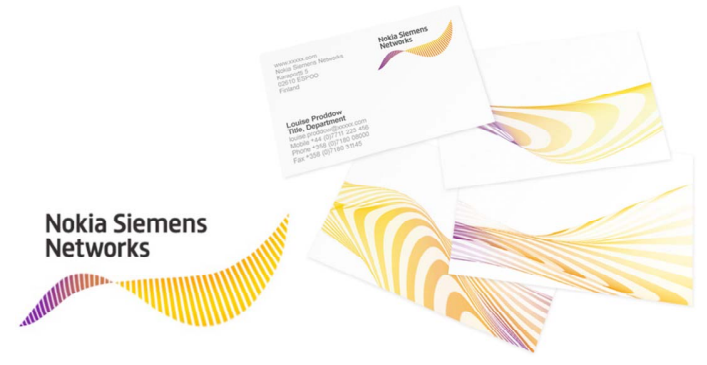

Figure 3.

Nokia siemens networks identity, moving brands (2007). 
cess. Therefore, the brand identity has three intersecting spotlights and is based on a visual system and a custom algorithm that can be set into 40,000 arrangements and 12 color-combinations. This is meant to reflect the constant redefinition of what media and technology means today. The algorithm produces a unique logo for each person. Each person can claim and own an individual shape and can use it on their business card, letterhead, web site, animations, a personal web site, signage, etc. A custom web interface was developed to allow each person at the Media Lab to choose and claim an own individual logo for his/her business card, as well as a custom animation software which allows the creation of custom animations for any video content the lab produces. The intersecting spotlight paths highlight the fluid collaborative approach that the institution takes in applying dynamic thinking to research and solutions (Allen, 2011).

Headquartered in New York, Seed Media Group is a diversified media, technology, and professional services company committed to advancing science and its potential to improve the state of the world. The identity is designed by Sagmeister, and the logo manifests science as looking at the world through the lens of the phyllotaxis (Macnab, 2008). In 2006, Seed Media Group commissioned Jonathan Harris to elaborate on this identity with digital media and information visualization. In 2008, Seed Media Group brought designers and scientists together for a conference organized in partnership with Parsons the New School for Design, MoMA, and also collaborated with Toshiko Mori and Michael Meredith at the Graduate School of Design at Harvard on a real-time data visualization project for the World Economic Forum. In 2009, Seed Visualization was founded and began to develop data visualization projects for companies and organizations. In 2010, Visualizing.org launched, the mission is to help make data visualizations more prominent across the web as a way of understanding complex world issues. The site is open and free and operates under the Creative Commons noncommercial license. It created a space for designers around the world to regularly upload and share their public work with a large audience and have it "used" by the public in discussions about issues like health, energy, climate, cities, food, and globalization (see Figure 4).

Cultural education industry: Take the Casa da Música (Porto city, Portugal) for an example, designer Stefan Sagmeister created the logo in a three dimensional form; it was then converted into six different logo marks comprising the top, bottom, north, south, east, and west views of the building. The Sagmeister

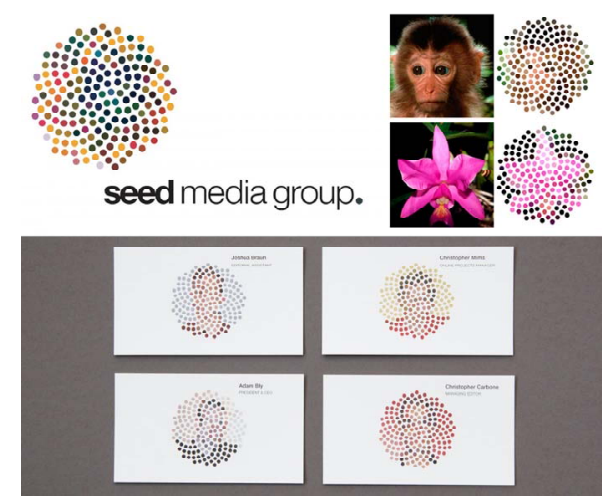

Figure 4.

Seed media group identity, Sagmeister (2008). team created seventeen points on the image, recording the color values of each point in the image, then transferred onto the 17 facets of the logo (see Figure 5). This provides the colors to be used in the logo, and creates an endless possibility. The architecture itself is a unique geometry, from different angles one can create different requests. The building is a visual element, and creates a dynamic, faceted and endlessly varied identity. Avoiding another rendering of a building, the design developed a system where this recognizable, unique, modern form transformed itself like a chameleon from application to application, where it changes from media to media, and where the physical building itself is the ultimate rendering in a long line of logos. Meanwhile, the goal was to show the many different kinds of music performed in one house. Depending on the music playing the house changes its character, and works dice-like by displaying different views and facets of the music (Albinson \& Giampietro, 2011).

The interactive design aesthetics operating process creates an involved feeling in the user, which surpasses participation itself, and through the result of chosen behavior reaches pleasure (Norman, 2004). From the individual cases above, the design thinking process integrates emerging technology, using the concept of data's automatic placement, mathematics, program calculation, and system module, creating a result of data visualization, and also derives unique design characteristics of customization and personalization. From a physical level of functionality in the definition of interactive design aesthetics, we classify this type of dynamic identity as "functionality" dynamic brand identity.

3) Psychological level of emotion

The biotechnology industry: Take 23andMe as an example, 23andMe is a privately held personal genomics and biotechnology company, founded in 2007, it develops new technology and methods in providing clients with genetic information. The company is named for the 23 pairs of chromosomes in a normal human cell. The variety of 23 distinct yet visually unified logos plays conceptually on the human chromosome, good for packaging and dynamic images. The visual space surrounding the identity is bright, but not stark, as this is one of the most unique visual elements, highlighting the boldness of 23andMe's unique immersion into consumer genetics. A single version is used consistently with the company name, but different colors and pattern variations can be used across application to create a variety in print pieces and on the internet. The form in the logo
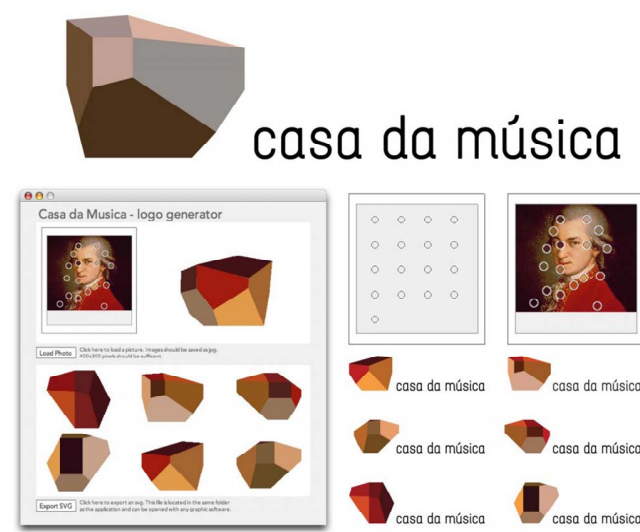

Figure 5.

Casa da música identity, Sagmeister (2007). 
represents chromosomes; their many and varied transparent colors show up again and again in unique combinations. Every one-that is, everyone-is different (Fishel \& Gardner, 2011) (see Figure 6).

Politic organizations: Take the 2008 American Democratic Party's Obama presidential campaign as an example. The logo was designed by Sol Sender on assignment from Chicago-based Mode Project motion design studio. The concept is the " $\mathrm{O}$ " of his name and has the idea of a rising sun and a new day; the sun rising over the horizon evokes a new sense of hope. In the 2008 Obama presidential campaign, different from the campaign trademark used before, there are two constant components for the Obama campaign identity. One is color (white and blue), and the other is the symbol (a sunrise with red stripes of the US flag at the base). Sender created a standard for a consistent identity system, and there is cohesiveness throughout, from the simple logo and how it expands and connects with people of different areas, via different media to different groups, aimed at different voters, such as Hispanic Americans, females, gays, bisexuals, and voters of various beliefs (Rawsthorn, 2008; Gomez-Palacio \& Vit, 2011) (see Figure 7).

Cultural education industry: Take the 17th biennale of Sydney as an example, the visual identity was designed by London designer Jonathan Bambrook, and the biennale's subtitle was inspired by American experimental filmmaker, anthropologist and musicologist Harry Everett Smith. He released a boxed set of historic recordings entitled The Anthology of American Folk Music in 1952. Barnbrook took inspiration from Everett Smith's work to develop a modular identity system for the festival comprising of a "myriad" of typefaces, shapes, patterns

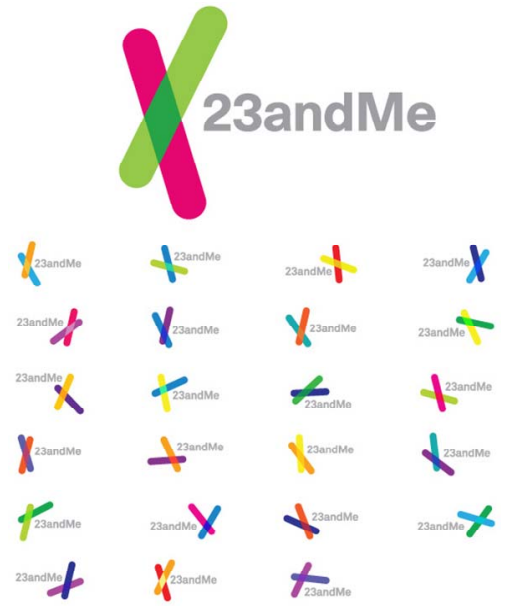

Figure 6.

23andMe identity, meta design (2007).
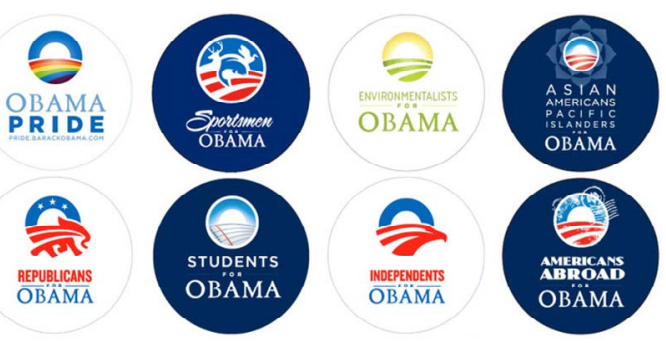

Figure 7.

Obama 2008 campaign identity, sender (2008). and illustrations that can be combined and applied to several activities. The identity is based around a modular system of blocks, the modular blocks are uniform in shape to allow for easy tessellation. There are two layers. One layer's blocks are of abstract shapes, and the other is of geometry and halftone printing techniques. The design showed a disorderliness containing word information and illustrations, drawn from old medical reference books, stills from Smith's films, astrological manuscripts, and the geometrical shapes from Victorian era medical illustrations, crystal structures, and mathematical text books. Many typefaces were designed by Bambrook himself; using typography as a modern language, an important element is the combined concept; using black, red and white, all the designs still contain flexibility and recognizablity, and can be applied to catalogue covers, websites, banners, posters and signages (Albinson \& Giampietro, 2011) (see Figure 8).

Interactive design aesthetics involves visual and tactile perception used in the same time, through vision to reach interaction, where interaction can surpass the visual contribution (Locher et al., 2010). Design thinking in this kind of identity system has diversity and extension, uses many collages, a module concept, sometimes uses static visual elements as the base, and uses different materials and art styles to change the visuals and provide pleasure and fun. From a psychological level and referencing interactive design aesthetics, we classify this type of dynamic identity as the "aesthetically pleasing" dynamic brand identity.

\section{Discussion}

In the process of synthesizing and collecting data, it was hard for this study to collect design related data in other languages, especially Japanese and Spanish, therefore, this study can only base conclusiongs on English-based data. Compiling data demanded accurate and definite brand identity system standards, design concepts and designers related information. Compiling 44 cases of dynamic brand identity, categorized by industry, information industry is $22.7 \%$, communications industry is $15.95 \%$, telecommunications industry is $6.8 \%$, traditional industry is $6.8 \%$, service industry is $11.36 \%$, cultural education industry is $20.5 \%$, media lab is $4.54 \%$, tourism industry is $4.54 \%$, biotechnology, welfare organization and politics organization industry is $2.27 \%$, Overall, telecommunications media and emerging technology related industries are $34.04 \%$. In global distributions of dynamic trademarks, US and Canada is $31.8 \%$, Europe is $54.59 \%$, Australia is $4.54 \%$, Asia is $6.8 \%$, South America is $2.27 \%$. Overall, countries distributed in Europe and America are at $86.39 \%$, the usage of dynamic brand identity outside of the Europe and America area are still mostly presented in the traditional static method (see Figure 9).

The study of interactive design aesthetics is divided into

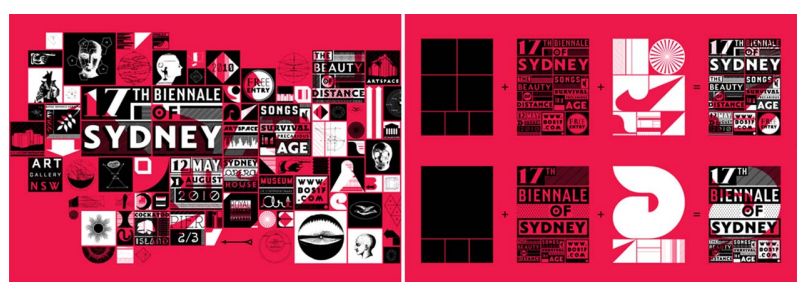

Figure 8.

The 17th biennale of Sydney identity, Bambrook (2010). 
experience and expression: studying someone using computational things (experience), and building computational things to be used by someone (expression), interactive design aesthetics holds a double focus on both issues, making the foundations somewhat different from traditional product design (Petersen, Hallnäs, \& Jacob, 2008). In dynamic brand identity seen from the viewpoint of "interactive design aesthetics", the "identification" is $20.5 \%$, "functionality" is $27.27 \%$, "aesthetically pleasing” is $52.23 \%$. For pleasure and entertainment the new media brings, Kerr, Kücklich and Brereton (2006) thought the core elements include control ability, situational immersion, storytelling, and narrative ability (Schrepp, Held, \& Laugwitz, 2006). The attraction of a product or brand with entertaining character has the same influence on the actual character, and the entertaining character is also an important element in creating fascination (Hassenzahl, Platz, Burmester, \& Lehner, 2000). Based on the analysis of 44 cases of dynamic brand identity and the basic design principle of a traditional brand-from the "identification" dynamic brand identity system, "functionality" dynamic brand identity, and "aesthetically pleasing" dynamic brand identity, we can also infer the design principle of the dynamic brand identity (see Figure 10).

The case analyses of this study showed that functionality adds the design principle of "customization" and "modularity"; and that entertainment could foster in people the desire of play, and curiosity could bring the exploration of learning materials, and that pleasure and entertaining elements exist in interactive design aesthetics. Dynamic brand identity with the "aesthetically pleasing”, concept in its design has diversity, extension, and uses lots of collage and modular elements. Or it uses basic static visual elements as base and different expressive materials and artistic style to change the visualization, and to be aesthetically pleasing and entertaining. Therefore, the emotion level enhances the design principles of "aesthetically pleasing” and "entertaining”, and a user's unique personality makes the brand identity have more emotions and activity, so the design princeple of "personalized" becomes ever more important (Rawsthorn, 2008) (see Figure 11).

\section{Conclusion and Suggestion}

This study is based on the analysis of 44 cases (see Table 1), which shows dynamic brand identity from the viewpoint of "interactive design aesthetics", and from recognition, functionality, and emotion. There are the "identification" dynamic brand identity, "functionality" dynamic brand identity, and "aesthe-

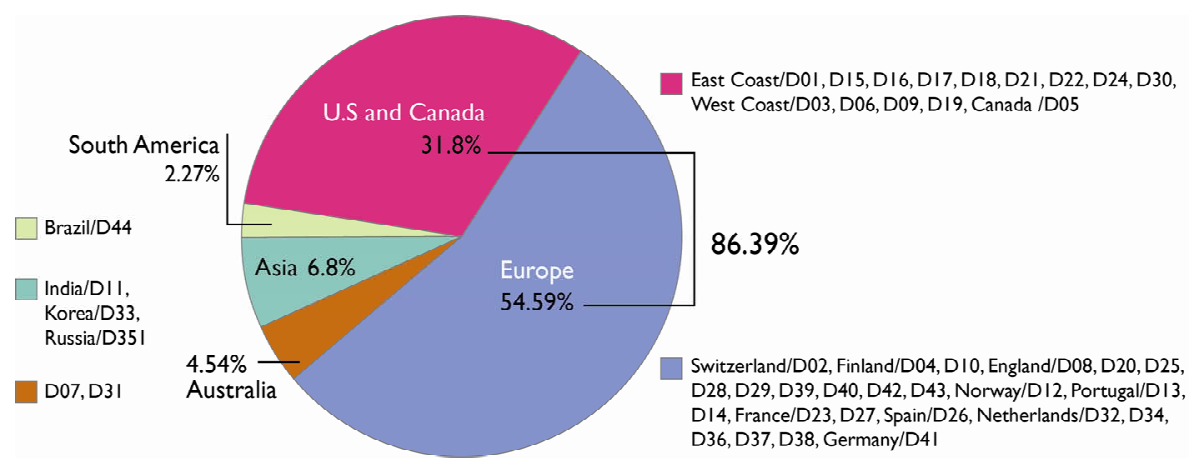

Figure 9.

44 cases of dynamic identity categorized by industry.

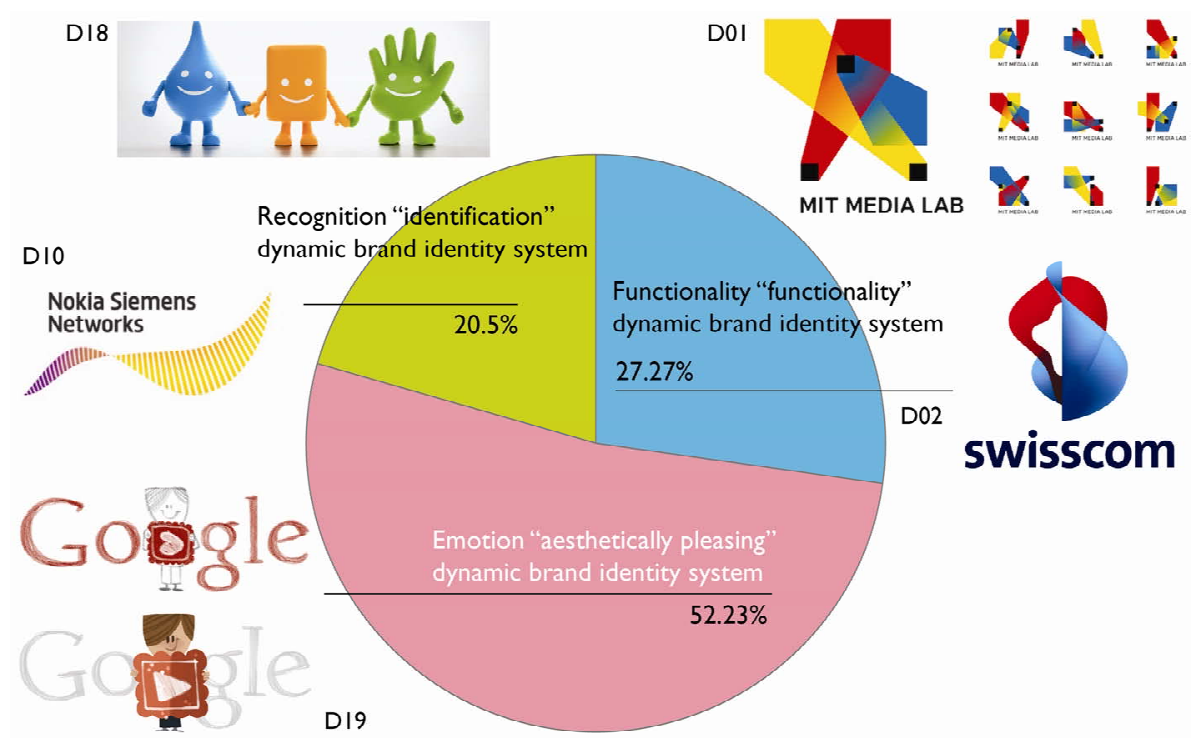

Figure 10.

44 cases of dynamic identity categorized by interactive design aesthetics. 
Table 1.

44 cases of dynamic identity.

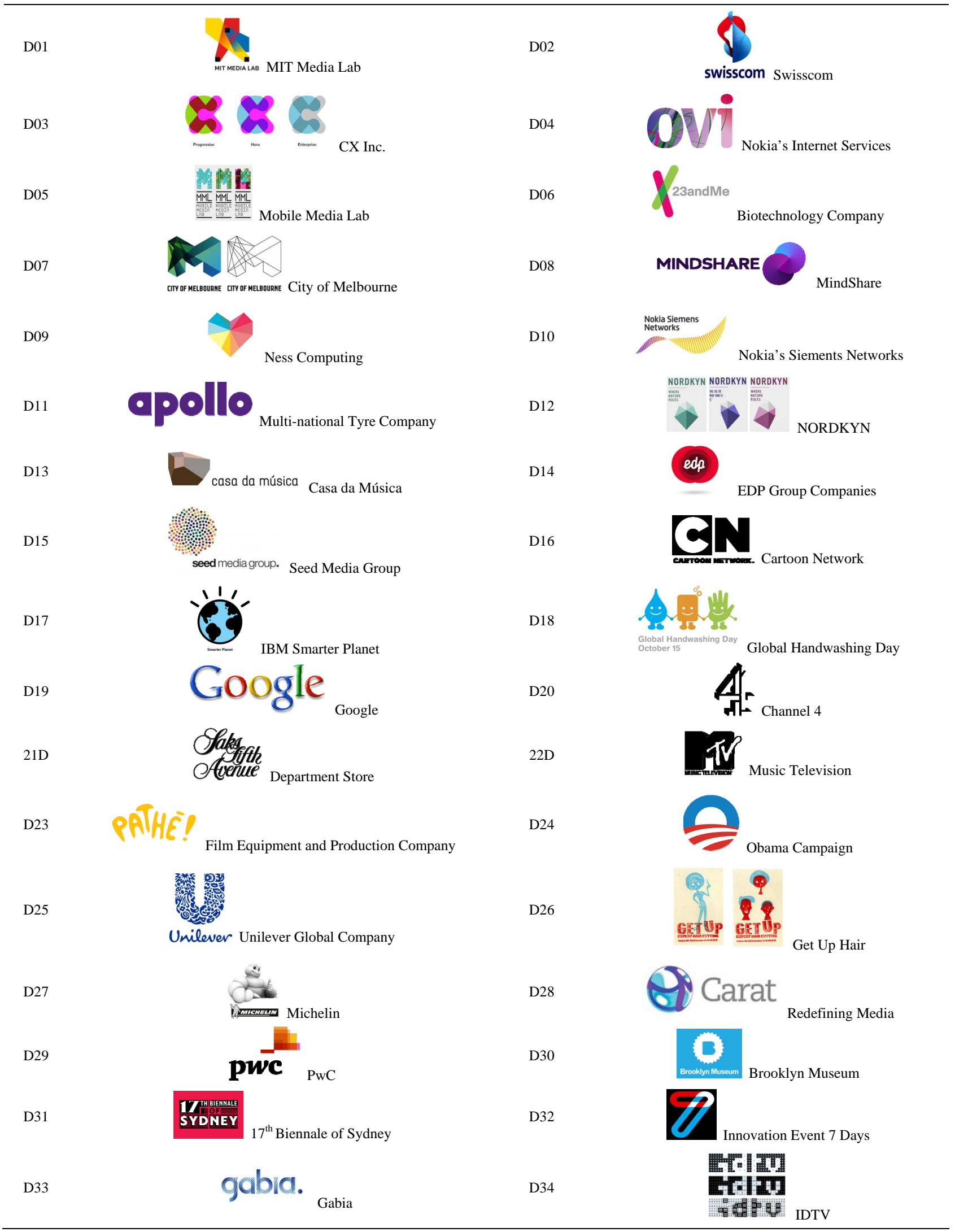




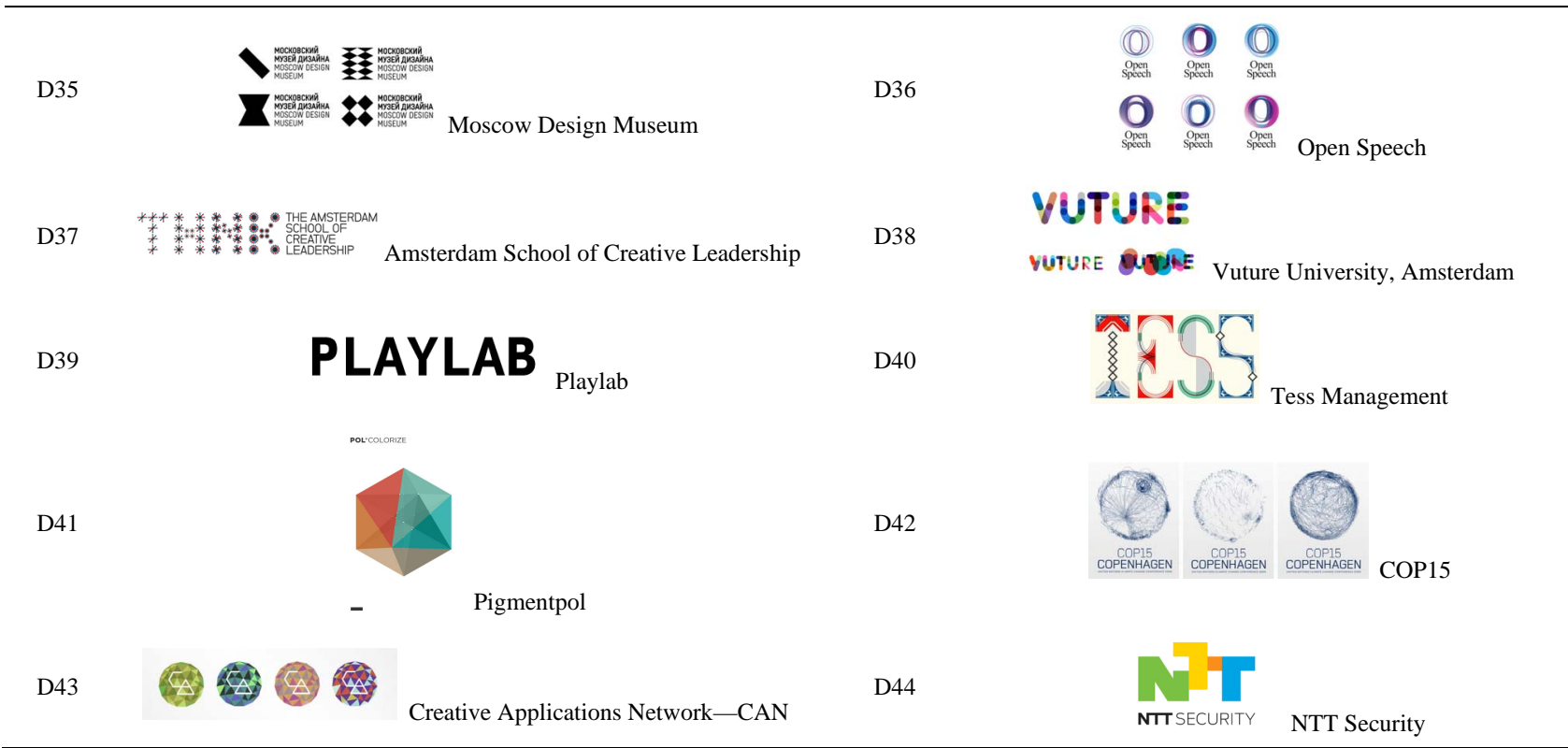

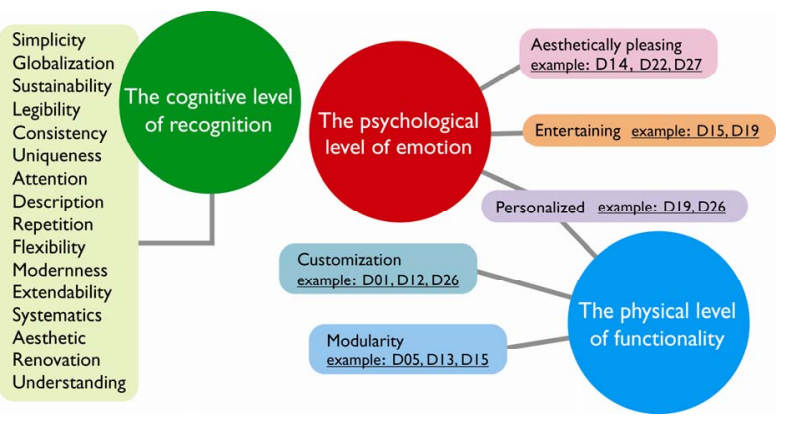

Figure 11.

Design principlesof dynamic identity.

tically pleasing” dynamic brand identity. In recent years, the trend of "functionality" dynamic brand identity has flourished, but the "aesthetically pleasing" dynamic brand identity, which uses different media and art styles to change the visualization, still has the largest percentage. Nowadays, designers face challenges in diverse expression, design elements and principles, aesthetic concepts and trends, and the audience's mentality and social media. In creative thinking, we still need to note if the design clearly fits the nature and personality of the brand, and transfer contents from the static image to the dynamic image.

While considering different communication media and platforms, we need to insert the whole brand identity concept, create a unique style of dynamic brand identity design; for the visual and tactile dimension of visual elements, we also have to consider cross-cultural and cross-ethnic issues. Design thinking should gradually integrate technology in the identity system, using both the concept of automatic data placement, mathematical operations, program algorithm, and system module, to create data visualization, and to also maintain design aesthetics from traditional brand identity, which is very important. Moreover, for different types of dynamic identities really convey the implications of the corporate brand, or what differentiation incognitive meaning there may be between various types of dynamic brand identities, there could be further discussions.

\section{REFERENCES}

Aaker, D., \& Joachimsthaler, E. (2002). Ch. 2: Brand identity-The cornerstone of brand strategy. In D. Aaker, \& E. Joachimsthaler, Eds., Brand leadership (pp. 33-50). New York: Free Press.

Albinson I., \& Giampietro R. (2011). Graphic design: Now in production. Minneapolis: Walker Art Center.

Allen (2011). MIT media lab’s unique new brand identity. http://aspirelondon.com/blog/articles/mit-media-labs-identity/

Baumgarten (1987). Aesthetics. Taipei: Culture and Arts Publishing House.

Budelmann, \& Wozniak (2010). Brand identity essentials: 100 principles for designing logos and building brands. New York: Quayside Pub Group.

Fishel, \& Gardner (2011). Logo lounge 6: 2000 international identities by leading designers. Beverly: Rockport Publishers.

Gomez-Palacio, B., \& Vit A. (2011). Graphic design, referenced: A visual guide to the language, applications, and history of graphic design. Beverly: Rockport Publishers.

Hassenzahl, M., Platz, A., Burmester, M., \& Lehner K. (2000). Hedonic and ergonomic quality aspects determine a software's appeal. CHI 2000, 2, 201-208.

Hsu, M.-C., Chen, C.-P., \& Chiu, C.-Y. (2012). Analysis of dynamic brands identity and the type of logo expressions. e-CASE \& e-Tech 2012, Hong Kong.

Kapferer, J.-N. (1992). Strategic brand management: New approaches to creating and evaluating brand equity. New York: The Free Press.

Kerr, A., Kücklich, J., \& Brereton, P. (2006). New media-New pleasures? International Journal of Cultural Studies, 9, 63-82. http://dx.doi.org/10.1177/1367877906061165

Lin, P. S. (1985). Cooperate identity system/CIS. Taipei: YTF Publisher.

Liu, P., \& Guan, J. Q. (2009). Three expression forms of logo designhyper-plane, dynamic and interaction. IEEE 10th International Conference on Computer-Aided Industrial Design \& Conceptual Design, Wenzhou, 26-29 November 2009, 1624-1627.

Locher, P., Overbeeke, K., \& Wensveen, S. (2010). Aesthetic interacttion: A framework. Design Issues, 26, 70-79. http://dx.doi.org/10.1162/DESI a 00017

Macnab, M. (2008). Decoding design: Understanding and using sym- 
bols in visual communication (p. 18). New York: How.

Mind Design (2011). Playlab.

http://www.minddesign.co.uk/show.php?id=265\&pos=6\&cat=2

Mollerup, P. (1999). Ch. 4: Taxonomy. In P. Mollerup, Ed., Marks of excellence: The history and taxonomy of trademarks (pp. 95-126).

New York: Phaidon.

Moving Brands (2007). Nokia siemens networks.

http://www.movingbrands.com/?category_name=nsn-work

Norman, D. A. (2004). Ch. 4: Fun and games. In D. A. Norman, Ed., Emotional design: Why we love (or hate) everyday things (pp. 99134). New York: Basic Books.

Norman, D. A. (2007). Ch. 3: Natural interaction. In D. A. Norman, Ed., The design of future things (pp. 57-90). New York: Basic Books.

Petersen, M. G., Hallnäs, L., \& Robert, J. K. (2008). ACM transactions on computer-human interaction. ACM Transactions on ComputerHuman Interaction, 15.

Rawsthorn (2008). The brand identity of Omaba. Taipei: International Creative Business.

Ross, P. R., Overbeeke, C. J., Wensveen, S. A. G., \& Hummels, C. C. M. (2008). A designerly critique on enchantment [Special issue on experience, enchantment, and interaction design]. Journal of Personal and Ubiquitous Computing, 12, 359-371.

http://dx.doi.org/10.1007/s00779-007-0162-3

Sharp, H., Rogers, Y., \& Preece, J. (2009). Ch. 5: Emotional interaction. In H. Sharp, Y. Rogers, \& J. Preece, EdS., Interaction design: Be- yond human-computer interaction (pp. 127-156). New York: Wiley. Schrepp, M., Held, T., \& Laugwitz, B. (2006). The influence of hedonic quality on the attractiveness of user interfaces of business management software. Interacting with Computers, 18, 1055-1069. http://dx.doi.org/10.1016/j.intcom.2006.01.002

Stamps, A. E. (2000). Psychology and the aesthetics of the built environment. Boston: Kluwer Academic Publishers. http://dx.doi.org/10.1007/978-1-4757-6326-3

Stone, T. L. (2010). Ch. 7: Aesthetic considerations. In T. L. Stone, Ed., Managing the design process (pp. 152-187). Beverly: Rockport Publishers.

Tremayne, M., \& Dunwoody, S. (2001). Interactivity, information processing, and learning on the World Wide Web. Science Communication, 23, 111-134. http://dx.doi.org/10.1177/1075547001023002003

Upshaw, L. B. (2000). Ch. 9: Creating the interactive identity. In L. B. Upshaw, Ed., Building brand identity (pp. 274-315). New York: John Wiley \& Sons Inc.

Vaid, H. (2003). Branding defined. In H. Vaid, Ed., Branding: Brand strategy, design and implementation of corporate and product identity (pp. 22-45). New York: Watson-Guptill Pubns.

Wang, G. T. (2005). Enterprises, brand, identity, image-Sybolic thinking and design logic. Taipei: Chuan Hwa \& Technology Book Co.

Wheeler, A. (2009). Designing brand identity: An essential guide for the whole branding team. New York: John Wiley \& Sons Inc. 